\title{
Excerpt From Alejandro Aravena
}

The following text is an excerpt from the conference opening keynote address by architect Alejandro Aravena. Aravena, the recipient of the 2016 Pritzker Architecture Prize, artistic director of the 2016 Venice Architecture Biennale and Executive Director of ELEMENTAL (Chile), proposed a new format for his keynote address. Instead of giving a lecture he held a unprecedented conversation with the audience. We could not capture this unique experience, but we have paraphrased a few fragments of this conversation in this text.

\section{CITY AS A SHORTCUT TO EQUALITY}

The city is a concentration of opportunities not a concentration of houses. That is why people come to cities. They come to be integrated into the network of opportunities. In many countries one of the biggest challenges is not poverty but inequality. The city reflects these inequalities in a brutal way. Chilean society is one of the most unequal societies in the world. Two thirds of the city population in Chile lives in a third world conditions. Every morning they have to take public transportation to come to the "first world", and then go back to the "third world." It is not surprising that the level of resentment, anger and social friction is high.
We often hear that the income re-distribution is the way to remedy the inequalities. So, the assumption is that you get better education, then better job with a better salary. Instead of being given a social housing unit, two hours away from here, you can choose where to live. And, instead of spending two hours a day in a public transportation you can buy a car and pay to drive on a private highway. So eventually, in a couple of generations, you improve your quality of life. But the city can work as a shortcut to equality. If you strategically identify projects of public transportation, public health, social housing, infrastructure and public space, you can correct some of those inequalities in a relatively short time.

If you could spend those two hours comfortably seated on an air-conditioned bus the journey from home to work becomes a good experience. By improving transportation the quality of life in the city improves. The public transportation should be good enough so that the person that owns the car would be willing to use it. The majority of the families in Santiago don't have income high enough to go on holidays. They depend on the free activities in the city. In Rio de Janeiro you have 50 kilometers of beach. All you need to enjoy the beach are flip-flops and a bathing suit. At the beach you can't tell who is rich or who is poor. The role of a public space in the city is to enable these moments of equality. On the peripheries of the cities like Santiago, where the houses are small and where people spend much of their time on the street, there is around 1-2 $\mathrm{m} 2$ of public space per person. In the central part of the city there is around 9-10

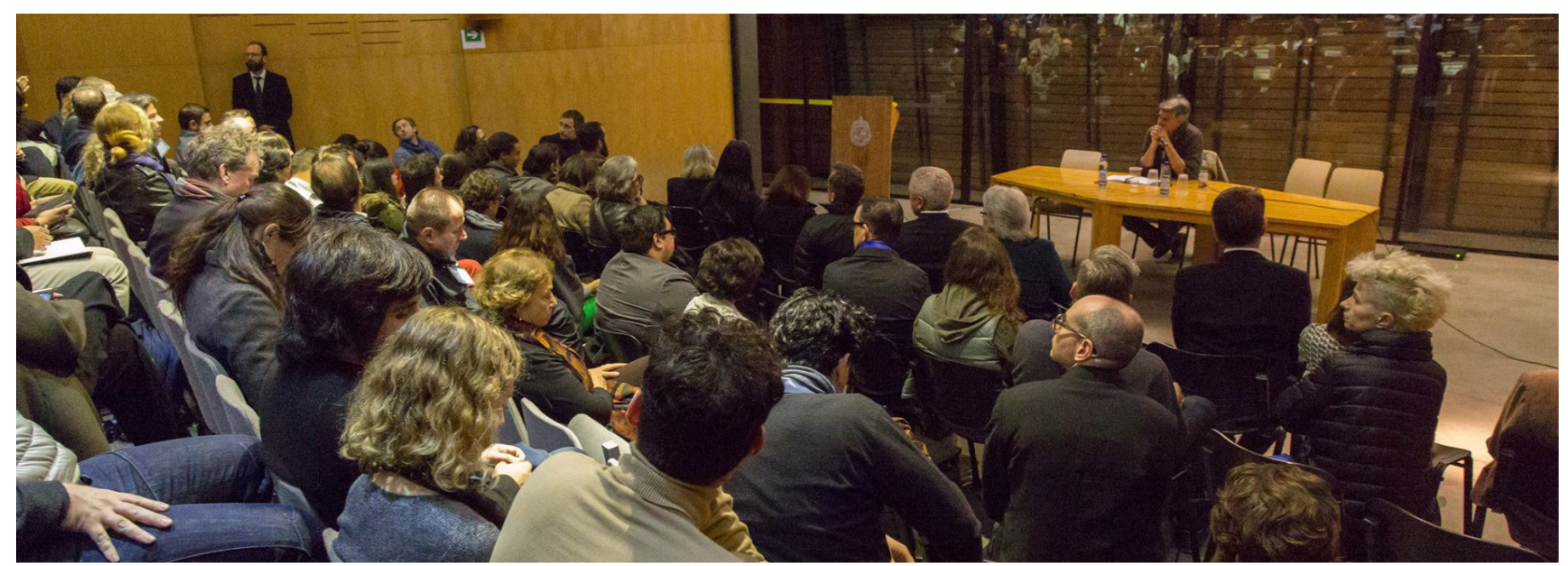

Figure: Opening keynote with Alejandro Aravena. 


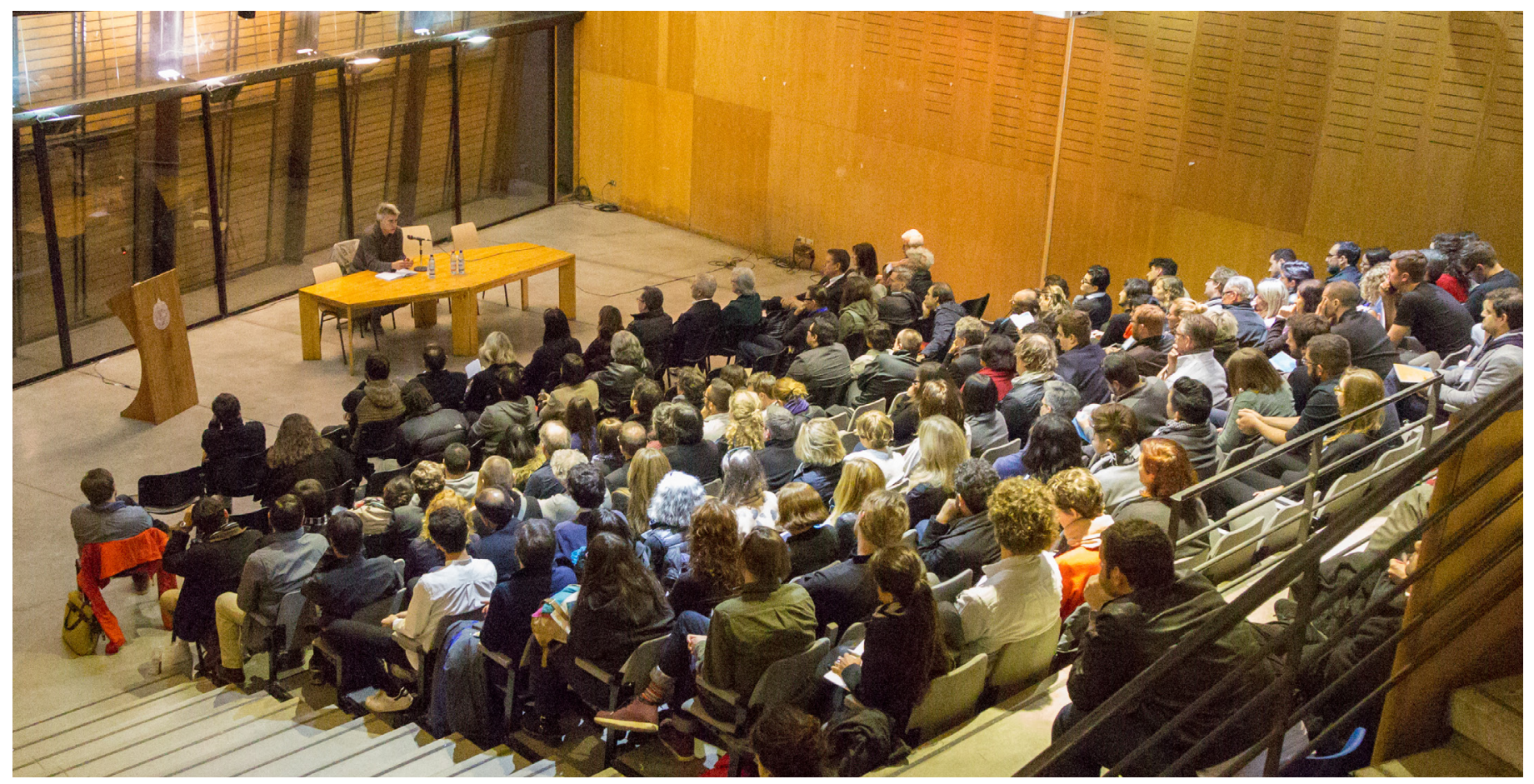

Figure: Opening keynote with Alejandro Aravena.

$\mathrm{m} 2$ of public space per person, and the wealthiest parts of Santiago have $18 \mathrm{~m} 2$. London on the other hand has $44 \mathrm{~m} 2$ of public space per inhabitant. So if you improve the quality and size of public space in the peripheries, you dramatically improve the quality of life there. If you identify projects that can make a change, a city can be a powerful mechanism for correcting inequalities. This is where we, as architects, can contribute.

\section{DO-TANK VERSUS THINK-TANK}

The concept of "Global" and "Disglobal" in relation to architecture runs a risk of becoming a theme. With this you are trying to formulate intelligent ideas that ultimately nobody cares about. We call our practice a do-tank and not a think-tank. If you want to be precise and not superficially address a given challenge, well, do it. Ultimately, what is transformed and transferred into a public realm is the building. So, by formulating an understanding of complex problems into a discourse, we run the risk of remaining trapped in that discourse.

As a profession we need to revisit the state of architectural knowledge. We should be able to make that knowledge travel as far as possible. Many of these exchanges happen face to face (as in this conference). A word and a face-to-face conversation are important in integrating the best standards and practices of "global knowledge" with local recourses.

If we want to talk, for example, about the building industry carbon footprint we cannot entirely separate that problem from the shortage of housing in the world.
To tackle these problems we need to talk not only about whether to go high-tech or low-tech, hyper-tech and no-tech, use plastics or other state of the art materials, we also need to address questions of unqualified labour, local materials and things produced by people that don't know much about the rest of the world. That is the extent of disparity we would have to bridge to address questions of carbon footprint and shortage of housing. We know that today's population is moving to cities. This is, in principle, good. But, from the 3 billion people living today in cities, 1 billion lives under the poverty line. By 2030 , it is likely that 2 billions will live under the poverty line. This means that we need to build housing for 1 million people per week with 10.000 dollars per family. Even if we cannot solve this equation people will keep coming to the city. They will live in slums, favelas and informal settlements. And eventually this will lead to a crisis. But even if we solve this crisis by continuing to build the way we do today, we will cause environmental crisis. President Obama said that the future treats for human societies would come from the climate change. So we are facing a serious dilemma. It seems that something completely unconventional will have to be done. I guess, we have to find a balance between knowledge that we haven't produced yet (global) and working with resources that are available in every single place (disglobal). That means that we might have to be more local than ever.

In our practice, ELEMENTAL, we choose projects by the amount of new knowledge we need to create to implement them. We like to keep learning. The Pritzker Prize offers us more freedom to choose those challenging projects that help us learn. 